\title{
Response to "Acute Hepatitis Induced by Lyprinol, the Lipid Extract of the Green-Lipped Mussel (Perna canaliculus), in a Patient with Polyarthrosis"
}

\author{
Stephen P. Myers ${ }^{1}$ and Christopher J. Oliver ${ }^{2}$ \\ ${ }^{1}$ NatMed-Research, Southern Cross University, Australia \\ ${ }^{2}$ Blackmores Institute, Australia \\ Correspondence should be addressed to Stephen P. Myers; stephen.myers@scu.edu.au
}

Received 16 May 2014; Accepted 11 August 2014; Published 20 August 2014

Academic Editor: John S. Koskinas

Copyright ( 92014 S. P. Myers and C. J. Oliver. This is an open access article distributed under the Creative Commons Attribution License, which permits unrestricted use, distribution, and reproduction in any medium, provided the original work is properly cited.

The title of the case report "Acute hepatitis induced by lyprinol, the lipid extract of the green-lipped mussel (Perna canaliculus), in a patient with polyarthrosis" [1] asserts a definitive causal relationship between Lyprinol and acute hepatitis. We are concerned that the report itself does not provide evidence that supports a definitive or highly probable association. As no rechallenge was undertaken definitive causality is impossible to prove.

The Council for International Organisations of Medical Sciences and Roussel Uclaf Causality Assessment Method (CIOMS/RUCAM) scale for drug-induced hepatotoxicity [2, 3 ] gives a score between 2 and 5 (see Table 1). The difference between these scores is dependent on information missing from the case report. At best this case report demonstrates that a causal association is possible. The Naranjo scale which is used to determine the likelihood of an adverse drug reaction [4] confirms this finding, giving a score of +2 which indicates the reaction is possible, as opposed to probable or definitive.

The subject had a six month history of recurrent, right sided epigastric pain radiating to her right shoulder and back and presented with an acute acerbation of this abdominal pain. On ultrasound of the gall bladder several concrements were found and it is therefore not possible to rule out that the episode of acute abdominal pain could be an episode of choledochal lithiasis.
The strength of the association in a single case report is determined by the absence of potential confounding factors. An important potential confounder in this case is that pantoprazole, which was being taken concomitantly with Lyprinol, has itself been the subject of multiple case reports of acute liver toxicity [5-7]. This confounder appears to be ruled out by the authors as the medication was stable at the time of the acute hepatitis. It is plausible, however, that an acute inflammatory flare occurred in an individual with known polyarthropathy and that this primed the liver toxicity in what had otherwise been a well-tolerated medicine. It is also possible that if pantoprazole was withdrawn at the same time as Lyprinol (not stated in case report) this may have caused the observed reduction in liver enzymes and improvement in the clinical picture, not the withdrawal of Lyprinol as was suggested.

Absent from the case report was basic information such as dosage of Lyprinol taken by the subject; indication of her height and weight; the specific diagnosis of her polyarthropathy; its contemporary history; and biological measures of its current severity (ESR and/or CRP).

Lyprinol is an extract of the green-lipped mussel which was a traditional staple of the diet of the New Zealand Maori people for hundreds of years and remains commonly eaten throughout New Zealand and Australia. It has been demonstrated to have anti-inflammatory activity [8] and is 
TABLE 1: CIOMS/RUCAM score for the case report on acute hepatitis induced by Lyprinol.

\begin{tabular}{|c|c|c|}
\hline Scale item & Scoring criteria & Score \\
\hline (1) Time of onset & Time from drug intake to reaction: first exposure 5-90 days & +2 \\
\hline (2) Course & Greater than $50 \%$ improvement in 8 days & +3 \\
\hline (3) Risk factors & Age over 55 years $+1 /$ alcohol-unknown & +1 \\
\hline (4) Concomitant drugs & $\begin{array}{l}\text { Concomitant drug known as hepatotoxin and with comparable or suggestive time } \\
\text { of onset }\end{array}$ & -2 \\
\hline (5) Alternative nondrug causes* & $\begin{array}{l}\text { Group 1: HAV serology +ve/alcoholism-unknown }=0 \\
\text { Group 2: Auto-immune polyarthropathy possible }=-3\end{array}$ & -3 to 0 \\
\hline (6) Previous hepatotoxic information & Reaction published but unlabelled & +1 \\
\hline (7) Response to rechallenge & Not undertaken & 0 \\
\hline & Total score & $2-5$ \\
\hline \multicolumn{3}{|c|}{ Interpretation: unlikely (2) to possible (5) } \\
\hline \multicolumn{3}{|c|}{$\begin{array}{l}\text { Explanation for variation on scale item 5-alternative nondrug causes: the RUCAM outlines two groups of nondrug causes of acute hepatitis that need to } \\
\text { be considered which are divided into two groups. Group } 1 \text { consists of recent HAV, HBV, or HCV; biliary obstruction; alcoholism; or history of hypotension } \\
\text { (particularly if there is underlying heart disease). Group } 2 \text { consists of complications of underlying disease and clinical or biological context for CMV, EBV, or } \\
\text { herpes virus infection. A score of } 0 \text { is given for } 5 \text { or } 4 \text { of Group } 1 \text { being excluded and -3 given if a nondrug cause such as acute autoimmune polyarthropathy } \\
\text { is highly probable. }\end{array}$} \\
\hline
\end{tabular}

not an obvious biological candidate for inducing direct liver toxicity. To date outside of the report by Abdulazim et al. only two other cases of hepatoxicity have been described in the literature and both of these cases had a weak association [9]. PharmaLink, the manufactures of Lyprinol, report that they have sold 700 million Lyprinol capsules in 39 countries over the past twelve and half years (McLean, N. PharmaLink Director. Personal Communication, August 2013). The low biological plausibility for direct toxicity and the small number of cases in a widely used dietary supplement suggests that any real hepatotoxic reaction has a high likelihood of being idiosyncratic.

A definitive causal relationship was not demonstrated in this case report and the paper's title is misleading.

\section{Conflict of Interests}

Stephen P. Myers and Christopher J. Oliver are on the Medical and Scientific Board of PharmaLink International Limited who own and license Lyprinol. Christopher J. Oliver is the Research Director for Blackmores Ltd which sells Lyprinol in Australia and New Zealand. Stephen P. Myers through Southern Cross University has research contracts with Blackmores Ltd. He also acts as a consultant to the Blackmores Institute.

\section{References}

[1] A. Abdulazim, M. Hadrich, M. Montani, and N. Semmo, "Acute hepatitis induced by lyprinol, the lipid extract of the green-lipped mussel (Perna canaliculus), in a patient with polyarthrosis," Case Reports in Hepatology, vol. 2012, Article ID 135146, 2 pages, 2012.

[2] G. Danan and C. Benichou, "Causality assessment of adverse reactions to drugs-I: a novel method based on the conclusions of international consensus meetings: application to druginduced liver injuries," Journal of Clinical Epidemiology, vol. 46, no. 11, pp. 1323-1330, 1993.
[3] C. Benichou, G. Danan, and A. Flahault, "Causality assessment of adverse reactions to drugs-II: an original model for validation of drug causality assessment methods: case reports with positive rechallenge," Journal of Clinical Epidemiology, vol. 46, no. 11, pp. 1331-1336, 1993.

[4] C. A. Naranjo, U. Busto, and E. M. Sellers, "A method for estimating the probability of adverse drug reactions," Clinical Pharmacology and Therapeutics, vol. 30, no. 2, pp. 239-245, 1981.

[5] C. Sandig, C. Flechtenmacher, W. Stremmel, and C. Eisenbach, "Pantoprazole induces severe acute hepatitis," Zeitschrift fur Gastroenterologie, vol. 49, no. 2, pp. 207-210, 2011.

[6] K. Darabi, "Proton-pump-inhibitor-induced hepatitis," Southern Medical Journal, vol. 98, no. 8, pp. 844-845, 2005.

[7] A. Cordes, W. Vogt, and K. P. Maier, "Pantoprazole-induced hepatitis," Deutsche Medizinische Wochenschrift, vol. 128, no. 12, pp. 611-614, 2003.

[8] M. W. Whitehouse, T. A. Macrides, N. Kalafatis, W. H. Betts, D. R. Haynes, and J. Broadbent, "Anti-inflammatory activity of a lipid fraction (Lyprinol) from the NZ green-lipped mussel," Inflammopharmacology, vol. 5, no. 3, pp. 237-246, 1997.

[9] S. Sukumaran, K. B. Pittman, W. K. Patterson et al., "A phase I study to determine the safety, tolerability and maximum tolerated dose of green-lipped mussel (Perna canaliculus) lipid extract, in patients with advanced prostate and breast cancer," Annals of Oncology, vol. 21, no. 5, pp. 1089-1093, 2009. 


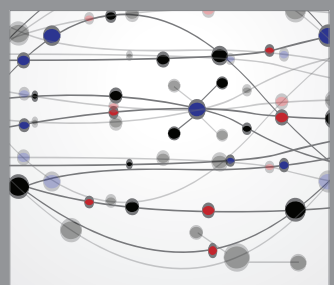

The Scientific World Journal
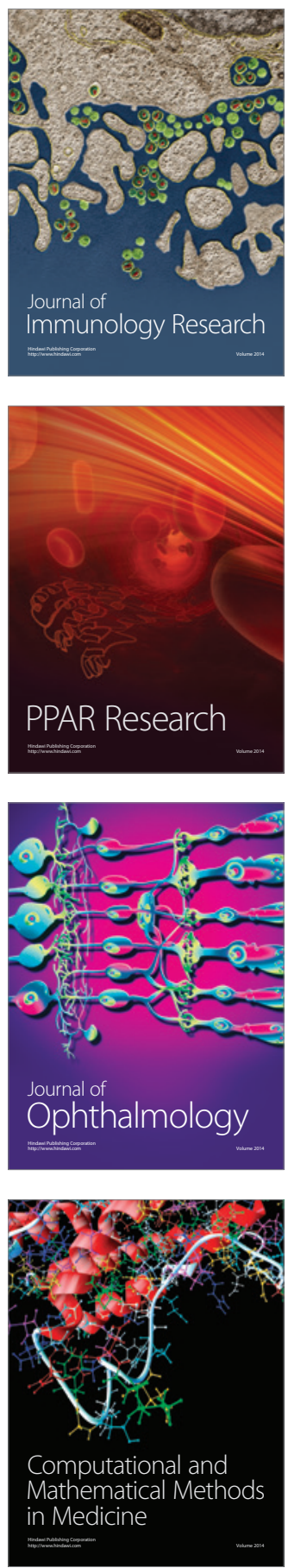

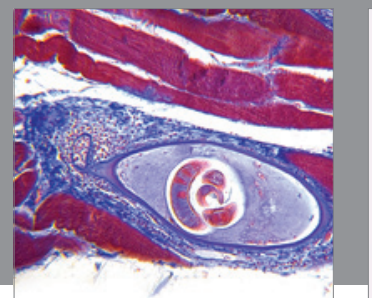

Gastroenterology

Research and Practice
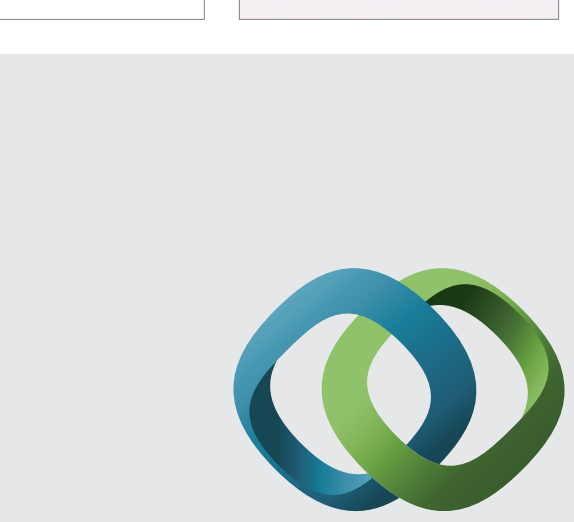

\section{Hindawi}

Submit your manuscripts at

http://www.hindawi.com
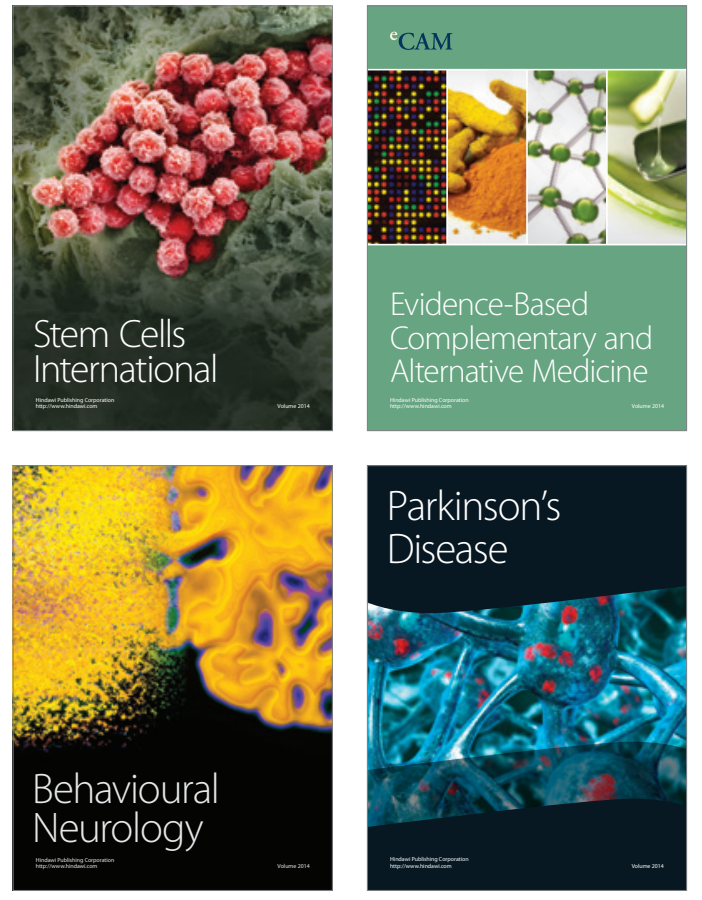
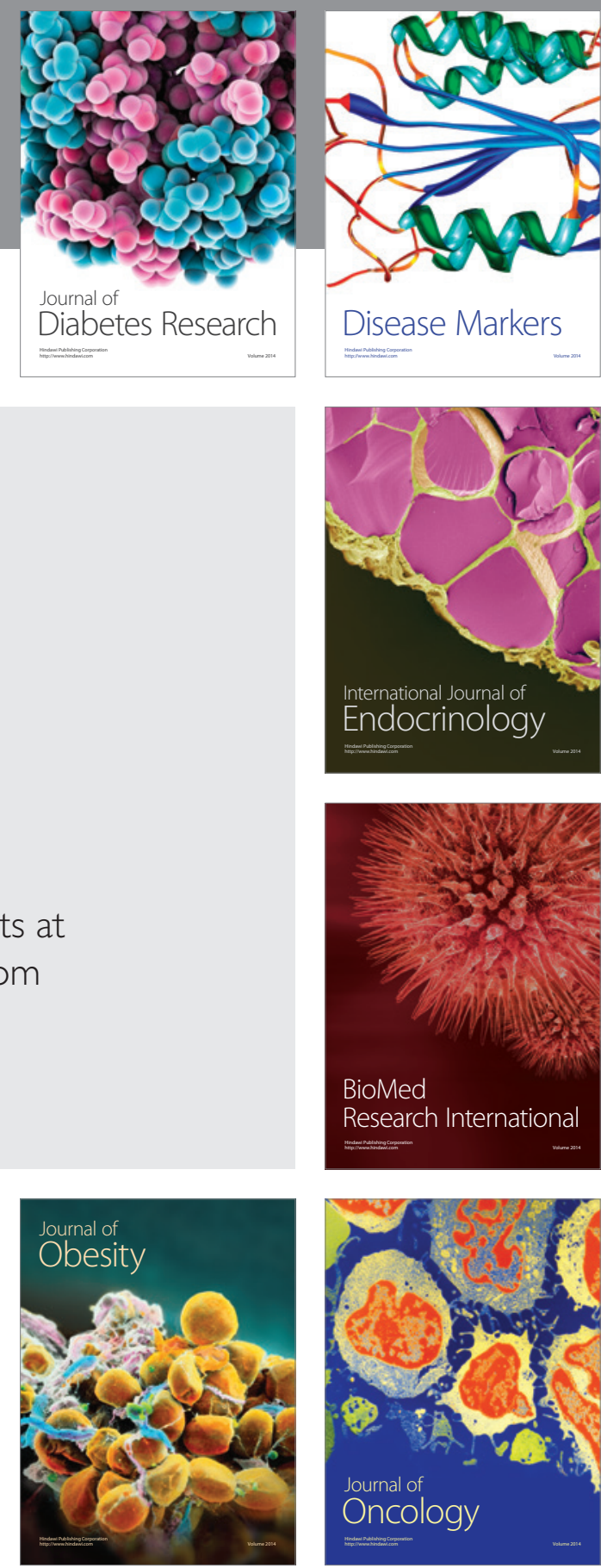

Disease Markers
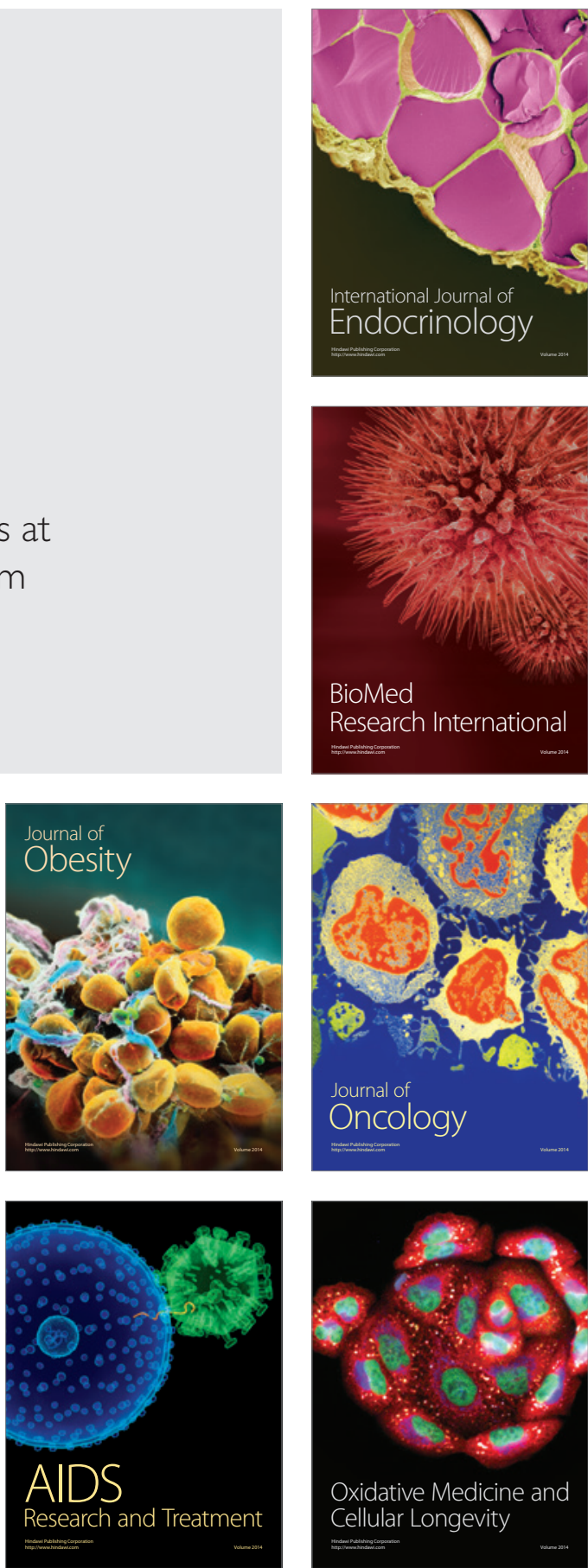